\title{
National CS Ed Equity-Focused Consortia and Their Value to the Community
}

\author{
Janice E. Cuny \\ (moderator) \\ National Science Foundation \\ 2415 Eisenhower Avenue \\ Alexandria VA 22314 \\ +1 7032928900 \\ jcuny@nsf.gov \\ Carol L. Fletcher \\ The Univ of Texas at Austin \\ 10100 Burnet Road MC R8700 \\ Austin TX 78758 \\ +15122325690 \\ cfletcher@tacc.utexas.edu
}

\author{
Jamie Payton \\ Temple University \\ 1925 N 12th Street \\ Philadelphia, PA 19122 \\ +12152048811 \\ payton@temple.edu
}

\author{
Ann Gates \\ The Univ of Texas at El Paso \\ 500 W. University CCSB 3.1002 \\ El Paso, Texas 79902 \\ +19157475480 \\ agates@utep.edu
}

\author{
Alan Peterfreund \\ SageFox Consulting Group \\ 30 Boltwood Walk \\ Amherst, MA 01002 \\ +14132566169 \\ apeterfreund@sagefoxgroup.com
}

\begin{abstract}
The Computer Science education community is supported by numerous national-focused consortia dedicated to addressing persistent inequalities in student pathways. This panel, comprised of leaders from four of those consortia (CAHSI, STARS, ECEP and RPPforCS) will use four key aspects of improvement communities as a framework for discussing the role, potential and impact of these consortia in supporting the equitable growth of computer science education. While not designed to be Network Improvement Communities per se, we draw upon those frameworks to focus on four specific aspects: 1) guided by shared goals with attention to equity; 2) engaging community in deep understanding of the problems and associated systems; 3) application of improvement science; and 4) coordinated efforts of shared learning and measurements. This will lead towards an open discussion with the audience focused on what has been empirically learned about the value these consortia have for their members and the broader CS Education community.
\end{abstract}

\section{CCS CONCEPTS}

- Social and Professional Topics $\rightarrow$ Computing education • Social and Professional Topics $\rightarrow$ Computing profession - computing organizations.

\section{KEYWORDS}

Broadening Participation, Diversity, Equity, ResearchPractitioner Partnerships, State Policies, Student engagement, Institutional change, Network Improvement

Permission to make digital or hard copies of part or all of this work for personal or classroom use is granted without fee provided that copies are not made or distributed for profit or commercial advantage and that copies bear this notice and the full citation on the first page. Copyrights for third-party components of this work must be honored. For all other uses, contact the Owner/Author.

SIGCSE '20, March 11-14, 2020, Portland, OR, USA

(C) 2020 Copyright is held by the owner/author(s).

ACM ISBN 978-1-4503-6793-6/20/03.

https://doi.org/10.1145/3328778.3366982

\section{Summary}

What role do consortia play in affecting efforts to address inequities in computer science education at the national level? First of all, it is hard work organizing and supporting members that are geographically dispersed, have agendas of their own associated with home institutions or organizations, are often way overcommitted and are often resources challenged - with time being the most valued resource. Yet, people have stepped forward to serve as part of a leadership team bringing these consortia to fruition and creating value for their members and supporting a national agenda of change.

In 2006, NSF awarded a set of grants to Alliances as part of the Broadening Participation in Computing program (Chubin and Johnson, 2010). These Alliance had a shared aim of addressing inequities in computer science education. The focus of each of these Alliances and the manner in which they formed and supported communities varied. The work of many of these Alliances has been sustained as part of ongoing entities or with their work embedded in new initiatives.

This panel will engage leaders of three of these Alliances (Computer Alliance of Hispanic-Serving Institutions - CAHSI, Students in Technology, Academia, Research and Service STARS Computing Corps and Expanding Computing Education Pathways - ECEP) along with a leader of a more recently formed consortium (Research-Practitioner Partnerships in Computer Science - RPPforCS) in a discussion on some of the guiding principles of the consortia and the value that has been created over time for the members and the broader community. The inclusion of RPPforCS, while not a BPC-A in origin and not as mature, was initiated with the benefit of lessons learned from that community and has as its core a commitment to equity through supporting and learning about deep engagement with practitioners.

One way to reflect on the consortia is consider them using the framework that supports Network Improvement Communities (NIC) (Bryk et al. 2011). While these consortia were not designed as NICs, the framework is useful for considering their evolution. The aspects that will be addressed by panelists will include four key aspects: 1) guided by shared goals with 
attention to equity; 2) engaging community in deep understanding of the problems and associated systems; 3) application of improvement science; and 4) coordinated efforts of shared learning and measurements.

The open discussion with the audience will focus on what has been empirically learned about the value these consortia have for their members and the broader CS Education community. Can local and/or national progress in addressing the inequities be directly attributable to the work of these consortia? If so, what aspects are deemed most responsible for contributing to these outcomes?

The intended audience are leaders and members of national consortia focused on equity in scaling and sustaining quality computer science education.

\section{Panel Structure}

The moderator initiates the conversation by contextualizing the role of consortia in supporting CS education and the framework by which the panelists will be discussing their organizations. (5 minutes) This will be followed by each of the presenters providing an overview of the evolution of their organization with a common thread associated with the four framing questions. (8 minutes per panelist). The remaining 30 minutes will be used for audience interaction, first with questions to the panel and then an open discussion of what has been empirically learned about the value these consortia have for their members and the broader CS Education community.

\section{Janice E Cuny}

Dr. Janice Cuny (Moderator) is the Program Director for Computing Education within CISE at NSF. In 2004, Janice founded the CISE Broadening Participation in Computing (BPC) program. It aims to significantly increase the number of students getting postsecondary degrees in computing, with an initial emphasis on those groups - women, minorities, and persons with disabilities - who have traditionally been underrepresented in computing. It has built a national community of several hundred researchers and practitioners who actively collaborate on interventions that address underrepresentation. In 2017, Dr. Cuny developed and co-directed the CSforAll-RPP Program.

\section{Ann Gates}

With National Science Foundation (NSF) Broadening Participation in Computing funding, CAHSI was formed in 2006 to address the low representation of Hispanics in computing in both higher education and the workforce through a unified effort involving administrators, faculty and professional staff, and entities from the public and private sectors. In 2018, CAHSI received funding from the NSF to be designated as a National INCLUDES (Inclusion across the Nation of Communities of Learners of Underrepresented Discovers in Engineering and Science) alliance. CAHSI's strategic actions are driven by a collective impact framework. CAHSI's community includes 20 higher education members and affiliates and 10 corporate and no-profit partners. Dr. Ann Quiroz Gates is a Distinguished
AT\&T Professor and Chair of the Computer Science Department and past Associate Vice President of Research and Sponsored Projects at the University of Texas at El Paso.

\section{Carol Fletcher}

Dr. Carol L. Fletcher is Director of EPIC (Expanding Pathways in Computing) at UT Austin's Texas Advanced Computing Center (TACC) where she oversees research and professional development projects in STEM and CS education such as the nationally recognized WeTeach_CS program. She serves as PI for the NSF funded Expanding Computing Education Pathways (ECEP) Alliance, a collective impact network of CS education leaders from 22 states and Puerto Rico focused on broadening participation in computing (BPC). ECEP seeks to increase the number and diversity of students in the pipeline to computing and computing-intensive degrees by supporting state-level computing education policies and supports. The ECEP model emphasizes building internal capacity in state leaders and supports states to address the diverse and intractable contextual factors that have stymied efforts to expand computing education pathways.

\section{Jamie Payton}

Jamie Payton is Chair of the Department of Computer and Information Sciences at Temple University and the Director of the STARS Computing Corps. Established in 2006 as an NSF Broadening Participation in Computing Alliance, STARS has engaged over 2700 students and faculty from 53 colleges and universities to develop cohort-based, student-led service learning projects to advance diversity, equity, and inclusion in computing within academic computing departments and their surrounding communities. STARS operates as a community of practice that includes faculty and students from institutions of higher education, working and learning together to develop leadership, knowledge, and resources for broadening participation in computing.

\section{Alan Peterfreund}

Co-leading RPPforCS with Rebecca Zarch (SageFox) and Leigh Ann Delyser (CSforALL) over the past two and a half years has been a great opportunity to bring together over 50 NSF-funded project teams from across the county that have been committed to equitable growth of CS education through deep engagement of researchers and practitioners. Through a connected community of practice, we have been sharing real-time experiences on how RPP can bring about meaningful change at the local, regional, state and national level. As Executive Director of SageFox Consulting Group, Dr. Peterfreund and his team have supported over 250 change initiatives in Computer Science and other STEM disciplines over the past 20 years.

\section{REFERENCES}

[1] Daryl Chubin and Roosevelt Johnson, Telling the Stories of the BPC Alliances, AAAS, June 2010;

[2] Bryk, A. S., Gomez, L. M., \& Grunow, A. (2011). Getting ideas into action: Building networked improvement communities in education. In Frontiers in sociology of education (pp. 127-162). Springer Netherlands. 